\title{
A PROTESTA AGRARIA DA BURGUESÍA AGROPECUARIA NA ARXENTINA CONTEMPORÁNEA. CONCENTRACIÓN DA PRODUCIÓN, RENDA DA TERRA E UNIDADE CORPORATIVA DA BURGUESÍA AGROPECUARIA, 1970-2008
}

Gonzalo SANZ CERBINO

IEALC / CONICET

camilogx@yahoo.com

Cidade Autónoma de Bos Aires, Arxentina

Resumo: Recentemente Arxentina viuse sacudida por un intenso proceso de mobilización da súa burguesía agropecuaria. Durante todo un ano, 2008, o país estivo pendente deste conflito, no que as corporacións agropecuarias se enfrontaron con virulencia contra 0 goberno nacional. A protesta agropecuaria non é nova, e dinos moitos das bases sobre as que se sustenta a economía nacional. Neste artigo faremos un percorrido polos principais conflitos que implicaron a esta fracción da clase dominante ao longo do século XX, prestando especial atención aos cambios e continuidades sofridos polo fenómeno. Intentaremos, a partir deste percorrido histórico, explicar non só os determinantes dos conflitos recentes, senón tamén algúns dos elementos que axudan a comprender o rumbo da economía arxentina e as súas crises máis recentes.

The agrarian protest in contemporary Argentina. Concentration of the production, land rent and corporate unit of agricultural bourgeoisie, 1970-2008

Abstract: Argentina has recently been shocked by an intense mobilization process of the agrarian bourgeoisie. For the whole 2008, the country held in suspense by the conflict, in which agricultural corporations confronted violently with the national government. Agricultural protest is not new, and tells us much about the basis on which the national economy is sustained. In this article we will review the major conflicts involving this fraction of the ruling class throughout the twentieth century, with special attention to the changes and continuities experienced by the phenomenon. We'll try, from this historical overview, to explain not only the determinations of the recent conflicts, but also some of the elements that help to understand the itinerary of the Argentina economy and its most recent crisis.

Palabras Chave / Keywords: Política agropecuaria, Conflito social, Burguesía agraria, Corporacións empresariais. Agricultural policy, Social conflito, Agrarian bourgeoisie, Interest Groups

\section{Introdución}

O ano 2008 foi para Argentina unha bisagra en termos económicos e políticos. Por unha banda, a recuperación económica consecuencia da crise de 2001 comezou a chegar aos seus límites. Por outra, houbo un extenso conflito que expresaba a ruptura da alianza social que sostiña ao goberno de Cristina Fernández de Kirchner. En marzo dese ano, a burguesía agropecuaria pampeana, grande e pequena, uniuse para resistir un intento de reforma do rexime de impostos ás exportacións de cereais. Co novo esquema, sancionado por decreto presidencial, os impostos aumentaban significativamente, e faríano aínda máis posto que a disposición establecía un aumento progresivo que acompañaría á tendencia á alza dos prezos internacionais de cereais e oleaxinosos.

Os representantes corporativos da burguesía agropecuaria comezaron manifestando o seu desacordo coa medida, pero rapidamente pasaron á acción. Inmediatamente declararon un "paro comercial" de 24 horas, nas que non remitían a súa produción aos mercados. 0 mesmo día da folga, realizáronse marchas de protesta en varios puntos do interior do país, onde os produtores agropecuarios desfilaron coas súas máquinas. Ante a ausencia de resposta, os líderes da protesta decidiron prorrogar a medida por unha semana e despois mantela por tempo indeterminado. A protesta agraria durou 129 días (con dúas "treguas" 
polo medio), ata que o goberno remitiu o paquete de medidas ás cámaras lexislativas, onde foi rexeitado. Esta fracción da clase dominante apelou á acción directa para torcer 0 brazo ao goberno, con mobilizacións nos centros urbanos, asambleas, actos multitudinarios e cortes de ruta en todo o país. No momento máis álxido, chegaron a manterse en simultáneo 311 cortes de ruta. Durante os catro meses que durou o conflito, a burguesía agropecuaria conseguiu entorpecer significativamente a circulación de mercadorías, o comercio interior e externo, o ingreso de divisas no país e o abastecemento interno de produtos básicos. O país estivo en albas en torno aos avatares da protesta, sofrendo as súas consecuencias.

A acción foi liderada polas catro corporacións empresarias máis importantes da burguesía agropecuaria da rexión pampeana, a principal zona produtora de materias primas exportables. As catro entidades uníronse nunha fronte denominada "Mesa de Enlace", que tiña poucos antecedentes na historia arxentina. Aló confluíron, por unha banda, a Federación Agraria Arxentina (FAA), fundada a principios do século XX por produtores capitalistas arrendatarios para defender o prezo dos arrendos fronte á burguesía terratenente. Actualmente, esta entidade está conformada polas capas máis pequenas da burguesía agropecuaria e por pequenos rendeiros expulsados da produción. Na fronte tamén participaron as Confederacións Rurais Arxentinas (CRA), entidade conformada pola burguesía terratenente media, e a Sociedade Rural Arxentina (SRA), que agrupa á burguesía terratenente de maior tamaño. Por último, á fronte tamén se incorporou a Confederación Intercooperativa Agropecuaria (CONINAGRO), que reúne a cooperativas de gandeiros e agricultores de todo o país, algunhas de gran tamaño. A unidad destas corporacións, cruzadas por enfrontamentos históricos que se manteñen ata a actualidade, fálanos da profundidade do conflito de 2008, pero tamén dunha serie de transformacións que sofreu a produción agropecuaria en Arxentina nos derradeiros 50 anos. Estas transformacións afectaron ás corporacións que expresan os intereses das distintas capas da burguesía agropecuaria, as súas formas de intervención política e os conflitos que a teñen por protagonista.

Neste artigo analizaremos as protestas protagonizadas pola burguesía rural pampeana nos últimos 40 anos, identificando ás fraccións mobilizadas, a forma de intervención e os motivos de conflito. Intentaremos reflectir os cambios que sofreu o fenómeno, así como as súas causas: as transformacións que afectaron ao suxeito que as protagoniza. Asemade, isto permitiranos coñecer certas características da economía arxgentina, que marcaron fortemente a súa historia social e política recente.

\section{A protesta agropecuaria a principios do século $\mathrm{XX}$}

Os conflitos protagonizados pola burguesía agropecuaria na primeira metade do século XX presentan un denominador común coas protestas dos últimos anos: xiran en torno á apropiación dunha ganancia extraordinaria xerada no agro polas calidades excepcionais da terra na rexión pampeana: a renda diferencial. Porén a diferenza dos conflitos da segunda metade do século, o enfrontamento involucrou exclusivamente a diferentes capas da burguesía agropecuaria. O que nestes momentos se presentaba como un enfrontamento interno, posteriormente aparecerá como un conflito entre todas as capas da burguesía agropecuaria e o Estado, en tanto representante doutras fraccións sociais que se disputan a apropiación da renda.

O conflito arquetípico desta primeira mitade do século XX foi o "Grito de Alcorta", unha rebelión de pequenos arrendatarios que, en 1912, reclamando melloras nos contratos de alugueiro da terra, iniciaron unha paralización das actividades produtivas, acompañada por actos e mobilizacións en toda a rexión agrícola. Estes conflitos eran consecuencia directa da caída dos prezos internacionais dos cereiais e das dificultades no mercado mundial xerados pola Primeira Guerra, que se sumaban a unha crise internacional de 
sobreprodución de cereais. Expresaban entón a disputa por unha renda que baixara nun contexto de crise internacional. As demandas xiraban en torno ao prezo dos alugueiros, aos seus prezos e ás condicións de comercialización (Grela, 1968; Halperin Donghi, 1984; Barsky e Gelman, 2009).

Os conflitos e as mobilizacións extendéronse ata os primeiros anos da década dos 20, impulsados por unha organización creada ao calor da protesta, a FAA, representante dos pequenos arrendatarios. O seu branco eran os grandes terratenentes reunidos na SRA. A mellora na situación internacional, a recuperación dos prezos, unha revolución técnica na colleita e o transporte, o aumento do rendemento e os resultados dun proceso de concentración e centralización de capital (a aparición das cooperativas), marcaron a fin deste ciclo de protestas agrarias ao comenzar a década de 1920, quedando como resultado a primeira lei reguladora dos alugueiros. Nembargantes, a crise mundial de 1930 reflotou o conflito: intentando aproveitar os mellores termos de intercambio para a gandería, os terratenentes comezaron a rescindir contratos de alugueiro e a expulsar da terra aos pequenos agricultores. A FAA retomou a mobilización para resistir os desaloxos, que recén acadara frear nos anos 40 coa intervención estatal sobre o mercado de alugueiros. A partir dalí, pouco a pouco comezaron a diluírse este tipo de conflitos.

A crise dos anos 30 tamén é o escenario no que aparece outro conflito típico da época, no que dúas capas da burguesía agraria se enfronta pola apropiación da renda diferencial: 0 enfrontamento entre gandeiros "criadores" e "invernadoiros". Na produción gandeira destinada á exportación diferenciábanse claramente dúas actividades: a cría, por unha banda, e o engorde nas terras preto do porto, nas que se producía o novillo de exportación ("invernada"). As dúas actividades coexistiron sen conflitos mentres a renda diferencial resultou suficiente para conformar a ámbolos dous sectores. Pero coa crise dos anos 30, na que xurdiron serias dificultades para manter as cotas de exportación gandeira, esta ganancia extraordinaria reduciuse substancialmente. Os que perderon foron os criadores, que pola súa situación como último elo da cadea produtiva, contaban con menos recursos para enfrontarse á nova situación. Isto deu lugar a unha escisión dentro da SRA, coa saída dos criadores que, cuestionando o dominio dos invernadoiros nesta entidade, crearon a Confederación de Asociacións Rurais de Bos Aires e a Pampa (CARBAP). Máis tarde, esa confederación formaría CRA, xunto a outras asociacións rexionais da burguesía terratenente media (Smith, 1986; De Olariaga, 1944).

Coa aparición da CONINAGRO na década dos 40, formada por cooperativas de comercialización asociadas na súa orixe a iniciativas dos pequenos produtores asociados na FAA, terminaríase de definir o mapa de organizacións corporativas do agro pampeano. A orixe de cada unha delas está asociado aos conflitos internos pola distribución da renda ao interior da burguesía agropecuaria, tendencia que comezou a revertirse nos 50 . 0 desenvolvemento do capitalismo arxentino tivo un punto de inflexión a mediados desa década. A partir dese momento, o país entrou nun ciclo errático no que fases de crecemento foron sucedidas por estruendosas caídas. Entre fase e fase, aparecía o fenómeno da crise de balanza de pagos, polo desaxuste entre as exportacións e importacións, e a crise fiscal. Isto poñía en evidencia o núcleo do problema da economía arxentina: o desenvolvemento dunha burguesía industrial ineficiente, incapaz de competir no mercado mundial, que se sostiña grazas á protección estatal con ingresos que viñan das exportacións agropecuarias. Cara a década de 1950, a contracción das magnitudes de renda agraria que ingresaban ao país comezou a esgotar os límites do sector rural para seguir sostendo este esquema económico. Exacerbouse entón a disputa interburguesa pola apropiación desta ganancia extraordinaria, nun contexto no que a crise de acumulación deu lugar rapidamente a unha crise política e social (O’Donnell, 2008; Iñigo Carrera, 2007). 


\section{As transformacións dos 60 e 70}

A intensificación da disputa pola apropiación da renda diferencial da tierra é un dos elementos que contribuiu a transtornar as formas de protesta da burguesía agropecuaria. A isto súmanse as transformacións estructurais do agro arxentino, sobre as que volveremos máis adiante. Os dous elementos operan xerando unha tendencia á confluencia das diferentes capas da burguesía agropecuaria (e das corporacións que as representan) nun bloque común, para enfrontar os intentos de apropiación de renda por parte doutros sectores sociais a través da mediación do Estado. Cara á década de 1960 a burguesía agropecuaria atopábase dividida en dous bloques enfrontados. Dunha banda, temos á burguesía terratenente media e grande, asociadas na SRA e CRA; doutro, aos pequenos propietarios e arrendatarios, asociados na FAA e CONINAGRO. O elemento que os dividía era a cuestión dos arrendamentos: dende a intervención estatal na década de 1940, os contratos foron prorrogados por decreto ata 1967, namentres os cánones de alugueiro foron fixados polo Estado ao longo de todo este período. Fronte a esta situación, o bloque terratenente esixiu sistematicamente a fin da intervención estatal sobre 0 mercado de arrendos, que afectaba os seus intereses. Os pequenos produtores, pola contra, defenderon a intervención e demandaron facilidades para que os arrendatarios puideran comprar os seus predios, xa que de levantarse a intervención serían expulsados da produción (Lázzaro, 2005). Pero baixo o manto dunha intervención que durou case 25 anos, a situación foise transformando, dado que moitos arrendatarios foron accedendo á propiedade, namentres que unha cantidade non menor terminou abandonando a terra. Así, o problema dos arrendamentos, último elemento de división dunha burguesía agropecuaria cada vez máis homoxénea, foi perdendo importancia.

Asemade, a oposición aos instrumentos cos que os diferentes gobernos intentaron capturar (e redirixir) a renda diferencial da terra foi gañando espazo nas demandas dos dous bloques da burguesía agropecuaria. Ao longo da década de 1960 multiplicáronse as protestas contra todo tipo de gravames que recaían sobre o sector, en especial os impostos ás exportacións ("retencións"). Asemade, foi común a protesta contra os tipos de cambio elevados, que abarataban internamente as divisas que obtiña o sector ao exportar, ou as protestas contra controis internos de prezos sobre bens primarios. Así, foise soldando un camiño que levaba á unidade corporativa da burguesía agropecuaria contra 0 Estado.

Cara 1965 ambos bloques coincidían en cuestionar unha política económica que quitáballe recursos ao sector agropecuario para financiar outros sectores. A FAA, por exemplo, cuestionaba o atraso cambiario e os impostos á exportación, unha protesta compartida polo resto das corporacións:

"Impulsados pola crecente necesidade de fondos que demandan os avultados déficits fiscais e os compromisos financeiros internacionais, o Estado seguiu unha política cambiaria sumamente prexudicial para o campo, ou ben a través do control do mercado de divisas ou por medio de retencións ás exportacións de produtos agropecuarios". ${ }^{1}$

A iso sumábase a protesta, tamén compartida, contra as folgas de pións rurais, que conseguiran arrebatar o que a burguesía agropecuaria toda consideraba "salarios desmedidos". ${ }^{2}$ Con estas protestas, as corporacións rurais sumáronse á alianza que promoveu o golpe de estado de 1966 (Míguez, 2013). O goberno dictatorial non

1La Tierra, 25/ 1/ 1966.

2La Tierra, 11/ 2/ 1966 y 4/ 3/ 1966; Memoria y Balance de la SRA 1965-1966, p. 72. 
contemplou na súa totalidade as demandas do agro. Como esixían os sectores rurais, a moeda devaluouse, pero se impuxeron novamente as retencións á exportación, que limitaban os beneficios que o agro acadaría co novo esquema cambiario. A iso engadíronse novas taxas, como o imposto á terra de 1968, que todas as corporacións cuestionaron por igual. Posteriormente, as catro corporacións obxetaron á súa vez os controis de prezos de certos bens agrarios, cos que o goberno pretendía frear a inflación. Así, a burguesía agropecuaria comezou unha fera campaña contra a política económica oficial, na que se foron sentando as bases para a conformación dunha fronte común. Os dirixentes das catro entidades comezaron a reunirse periodicamente e a emitir documentos conxuntos obxectando medidas oficiais. ${ }^{3}$ A mediados de 1970 multiplicáronse as asambleas e actos en todo o país, nos que se denunciou o "afogamento" do campo como resultado da política agropecuaria nacional. ${ }^{4}$ As referencias á necesidade de acadar a unidade do campo foron reiteradas polos dirixentes corporativos de todas as tendencias, tanto nesas asambleas como en documentos conxuntos presentados ás autoridades. ${ }^{5}$

Finalmente, os esforzos frutificaron na convocatoria a unha asamblea conxunta por parte da SRA, FAA, CRA e CONINAGRO, na que se discutiría a conformación dunha fronte común. A asamblea, realizada os días 26 e 27 de octubre de 1970 en Santa Fe, contou coa participación do máis selecto da dirección agropecuaria. Os que se expresaron nela coincidiron en criticar a política económica oficial, en particular, as elevadas taxas da renda instrumentada polo goberno a través de mecanismos fiscais e cambiarios. Tamén insistiron unha e outra vez na necesidade de unificar ás catro corporacións agropecuarias para enfrontarse a esta política, e ese foi o compromiso ao que se chegou ao concluír o mitin $^{6}$. A fronte formalizaríase nunha segunda asamblea, realizada en novembro de 1970, na que se deron cita 10.000 delegados orixinarios de todo o país. Aló resolveuse a conformación da Comisión de Enlace, a fronte que integrarían as catro corporacións que convocaron o encontro. ${ }^{7}$ Asemade votouse un programa, que cuestionaba a política agropecuaria dos últimos 30 anos, obxectando o saqueo permanente de recursos ao agro destinados (segundo o contido do documento) ao sustento dun estado sobredimensionado, unha burguesía industrial ineficiente e un nivel de consumo das masas incompatible co crecemento da única actividade económica capaz de impulsar o desenvolvemento do país: o agro $^{8}$. O programa era moi claro en unir ás corporacións agropecuarias: a loita na defensa dunha ganancia extraordinaria, a renda diferencial da terra, disputada e apropiada por outros sectores sociais a través da mediación estatal.

A Comisión de Enlace estivo funcionando ata 1973, e incluso acadou un éxito importante ao conseguir impoñer a un dos seus impulsores, o presidente da FAA Antonio Di Rocco, como Ministro de Agricultura e Gandería en 1971. Nembargantes, a nova situación política e económica aberta en 1972 conspirou contra os esforzos unitarios. O aumento dos prezos internacionais das mercadorías agropecuarias restaba urxencia á necesidade de unirse para combater a apropiación estatal da renda, namentres que o ascenso da loita de clases motorizado polo ciclo insurreccional aberto en 1969, obrigaba a ensaiar políticas reformistas que contivesen a axitación popular. A Comisión de Enlace non sobreviviu aos desafíos da nova etapa que se abría no país, malia que as tendencias á unidade do campo seguirían latentes.

3La Nación, 15/ 4/ 1970, 28/ 5/ 1970 y 4/ 8// 1970.

4La Tierra, 16/ 7/ 1970, 6/ 8/ 1970 y 28/ 8/ 70.

5La Nación, 4/ 8/ 1970, 9/ 8/ 1970 y 19/ 9/ 1970.

6La Nación, 26 y 27/ 10/ 1970.

7La Nación, 18 y 19/10/1970.

8CRA, SRA, FAA, CONINAGRO y CCEA: El agro y el desarrollo nacional. Conclusiones, Buenos Aires, 17 de noviembre de 1970. 
A dictadura iniciada en 1966 derribouse en medio dunha xigantesca crise do rexime. Para conter a eclosión social viuse na obriga de convocar eleccións libres, que permitisen a participación do peronismo, forza política proscrita dende 1955. Este partido fíxose co triunfo en 1973, inaugurando un período caracterizado por unha política reformista, onde os niveis crecentes da renda diferencial da tierra foron apropiados mediante a centralización estatal do comercio exterior de carnes e grans, e destinados a soster o crecemento dunha industria urbana que, aínda así non conseguiu sortear as súas limitacións históricas para competir nun mercado mundial. O goberno peronista obtivo da burguesía agraria un amplo apoio, que se traducía nunha aceptación de altos niveis fiscais da renda, xa que, dado o nivel que acadaron os prezos internacionais, podían seguir disfrutando dunha rendibilidade elevada. Nembargantes, a conxuntura internacional favorable comezou a reverterse cara 1974, primeiro coa caída dos prezos gandeiros e despois, cara 1975, cun derrube estrepitoso dos prezos dos grans nos mercados externos.

Dende mediados de 1974 comezou a intensificarse a prédica opositora das corporacións agropecuarias contra a política económica gobernamental. O principal desacordo eran os baixos prezos que o Estado fixaba para os produtos primarios. Isto debíase a que coa estatización do comercio exterior de grans e carnes, o mecanismo privilexiado para a apropiación de renda pasou a ser o nivel de prezos internos, que se fixaban nunha cantidade inferior á cotización internacional. Con esta demanda á cabeza, as distintas corporacións comezaron a romper os seus vencellos co goberno e, a finais de 1974, xa formaban unha nova fronte opositora: o Comité de Acción Agropecuario (CAA). Á iniciativa unitaria sumáronse o CRA, SRA e CONINAGRO. A FAA mantívose lonxe, polas esperanzas que gardaba nas iniciativas reformistas que impulsaba o goberno, especialmente as vencelladas aos cambios na estructura de propiedade da terra. ${ }^{9}$ Isto non impediu que a FAA fora unha das máis críticas coa política de prezos baixos e, de feito, foi a primeira en pasar á acción cando o goberno abandonou os seus plans de reforma. A comezos de 1975 xurdiron unha serie de conflitos rexionais protagonizados por gandeiros e agricultores. Todos eles derivaron en folgas comerciais agropecuarias con duracións variables, de entre 1 e 15 días. Entre xaneiro e marzo de 1975 houbo oito folgas rexionais para reclamar mellores prezos para os produtos primarios. En todos eles participou a FAA. Todas as accións foron acompañadas por mobilizacións e cortes de ruta que axudaban a garantir que ninguén enviaba a súa produción aos mercados..$^{10}$

O CAA tentou capitalizar clima de descontento convocando unha folga comercial agropecuaria de alcance nacional o 3 de marzo, que se cumpriu con alta participación. Este foi a primeira dunha serie de folgas agrarias que ese ano sacudiron o país, contribuíndo a xerar un clima de desestabilización que abonaba o golpe de estado que xa se estaba xestando. O CAA finalmente se disolveu por diferenzas internas con respecto á profundidade do enfrontamiento. Porén, recén disolto xurdiu unha nova alianza, entre a FAA e o CRA, que impulsou o resto das folgas comerciais dese ano. En abril esta alianza realizou unha nova folga, esta vez por tres días, acompañado tamén pola mobilización das bases corporativas e cortes de ruta. En maio, convocouse unha nova acción por tres días, á que se sumou a SRA. Na segunda metade do ano o clima político enrareceuse e o conxunto da burguesía comezou a mobilizarse a favor dun golpe de estado. A burguesía agraria, sempre colocando como reclamo principal o cuestionamiento aos mecanismos do Estado para capturar e redirixir a renda da terra, sumouse con dúas novas folgas comerciais. En setembro o CRA, a FAA e a SRA convocaron unha folga que durou 11 días, e en outubro a unha nova acción durante 18 días. Pola súa extensión, as dúas causaron serias

9La Nación, 10/ 7/ 1974; La Tierra, 3/ 10/1974.

10Unha reconstrución minuciosa destas mobilizacións pódese atopar en Sanz Cerbino (2009). 
complicacións a un goberno tocado por unha profunda crise: problemas de abastecemento e aumentos de prezos nun contexto xa marcado pola inflación. Estas corporacións contribuíron, desta maneira, a desestabilizar a un goberno apancado, que non atinaba en ofrecer respostas a unha profunda crise social e política. Finalmente, en marzo de 1976, o goberno peronista terminou sendo desprazado por un golpe de estado altamente represivo. A burguesía agropecuaria, que impulsara o golpe, apoiou ao novo rexime e introduciu a algúns dos seus dirixentes a funcións de goberno (Sanz Cerbino, 2009).

\section{A consolidación dun novo esquema de protesta no agro}

Durante a ditadura, que se produciu entre 1976 e 1983, non houbo mobilizacións da burguesía agropecuaria, pero si protestas. Especialmente a partir de 1980, cando comenzaron a cuestionar os aspectos da política económica que consideraban prexudiciais para o sector. Novamente, pronunciáronse contra as cargas fiscais, as retencións e unha política cambiaria que implicaba a resignación dunha parte substancial da renda diferencial da terra que fluía cara outros sectores (Sartelli et al., 2008: 283-285). Coa restauración democrática a burguesía agropecuaria volveu a apelar ás folgas comerciais agropecuarias, unha modalidade de protesta que comezaba a consolidarse como o medio elixido por este sector para que se escoitase o seu descontento. A comezos de 1985, o CRA e a SRA acudiron á Capital Federal con vehículos e maquinaria agrícola, no que se terminou chamando o "camionetazo". Tamén realizaron dúas xornadas de protesta con actos e mobilizacións no interior do país. En abril de 1986, a FAA e CONINAGRO sumáronse ao CRA e SRA, participando as catro entidades nunha xornada de protesta. En xuño dese ano o CRA e a SRA realizaron unha folga nacional agropecuaria, namentres que a FAA se mobilizaba na denominada "Marcha da miseria". En 1988, as catro volveron unirse en dúas "Xornadas de protesta e proposta". As súas demandas durante todo o período seguiron xirando en torno á marcada oposición aos mecanismos oficiais para capturar e redirixir a renda da terra, en particular as retencións ás exportacións e a aplicación de tipos de cambio diferenciais (Sartelli et al., 2008: 283-285).

Nos 90, xa cun novo goberno e un marcado xiro na política económica, a protesta agropecuaria intensificouse. O presidente Menem, avanzando unha política de corte liberal, non prescindiu dos mecanismos destinados a redirixir a principal fonte de riqueza do país, a renda da terra. Non recorreu a impostos ou retencións, pero si afectou os ingresos do sector agropecuario cunha política cambiaria que abarataba as divisas restando ingresos aos exportadores. Asemade, a política económica acentuou o proceso de concentración e centralización da produción agropecuaria, expulsando ás fraccións máis débiles do campo. Por estas razóns, a mobilización da burguesía agropecuaria foi permanente durante a década. En 1991 a FAA, CRA e CONINAGRO realizaron unha folga comercial de dous días. En 1992, unha nova folga foi convocada pola SRA, CRA e CONINAGRO. As mesmas corporacións mobilizaríanse a mediados de 1993 nunha "tractorada", unha marcha con vehículos e maquinaria agrícola cara os centros urbanos. En 1994 a FAA, CRA e CONINAGRO participaron da "Marcha Federal", unha mobilización masiva que reuniu a todo o arco opositor ao goberno. Ese mesmo ano, o CRA, CONINAGRO e SRA realizaron unha folga comercial de nove días de duración. A partir de 1996, os efectos do proceso de concentración empezaron a sentirse fortemente: as execucións xudiciais de debedores bancarios foron a forma que asumiu a expulsión de pequenos produtores do agro. A FAA, a entidade que os xuntaba, cobrou protagonismo. En 1996 lanzou unha "semana de protestas", con mobilizacións en todo o país en protesta pola refinanciamento das débedas e a suspensión dos desaloxos. En 1997 realizáronse unha serie de "tractoradas" impulsadas pola entidade en localidades afectadas por unha 
profunda sequía, e en 1998 a FAA protagonizou unha serie de mobilizacións contra o aumento dos impostos e esixindo axuda para os produtores afectados polas inundacións. Ese mesmo ano, o CARBAP realiza unha folga comercial pola súa conta. En abril de 1999 recuperouse a senda unitaria, cando as catro corporacións impulsaron unha folga comercial por dous días. En xuño dese ano CRA, CONINAGRO e FAA convocaron a unha nova folga por tres días, e en setembro foi só a FAA a que recorreu á folga, novamente por tres días. Polo medio, tamén se realizaron mobilizacións á Capital Federal e actos no interior. Mentres o país encamiñábase a un novo estoupido social, en 2000, o CRA, FAA e CONINAGRO convocaron unha nova folga comercial de tres días. Asemade, as entidades participaron da conspiración que desprazou ao presidente De la Rúa en 2001.11

En 2001 xurdiu unha crise que se viña incubando durante moito tempo. Despois de varios anos de recesión económica, déficit fiscal e desequilibrio externo, o estado finalmente quebrou cando se cortou o financiamento externo. Non se podía pagar a débeda externa e nin os salarios dos empregados públicos, unha corrida bancaria ameazaba con quebrar 0 sistema financeiro e a mobilización social ameazaba ao goberno. Finalmente, logo de dúas xornadas de mobilización social en todo o país, o presidente terminou renunciando. Os seus sucesores declararon o default e a depreciación da moeda. Porén, a axitación social impedía descargar toda a magnitude do axuste sobre as masas, e comezaron a ensaiarse esquemas para conter a inflación. Unha batería de subsidios destinouse a conter a alza das tarifas de servizos públicos, ao tempo que se multiplicaban os plans de axuda social e as transferencias cara a burguesía industrial para soster a reactivación económica. En ausencia de financiamento externo, o goberno recorreu novamente á renda (tanto agraria como petroleira), impoñendo impostos á exportación que axudarían a recuperar a economía e a conter a eclosión social. A alza dos prezos internacionais dos grans foi un alicerce que permitiu unha morna recuperación económica nun país que comezaba a saír do pozo.

Xa en 2003, o CRA, FAA e SRA convocaron unha folga de cinco días polas presións fiscais. En 2006, o goberno impulsou medidas para conter a inflación, entre elas o peche das exportacións de carne e restriccións á comercialización de trigo e lácteos. Este paquete sumábase ás retencións, que non só servían para financiar ao estado senón tamén como medida de contención dos prezos. Frente a isto, o CRA convocou unha folga de catro días, á que se sumaron só algúns sectores internos da FAA. A dirixencia agropecuaria aínda estaba dividida dado que os ingresos eran altos e a reconstitución da dominación ameazada pola intensa mobilización social despois de 2001 obrigaba a facer certas concesións. Nembargantes, o peso crecente das cargas sobre o agro espallaba o descontento no sector e, a finais de 2006, convocouse unha folga de nove días, na que participaron a SRA, CRA e FAA. A mobilización da burguesía agropecuaria foi importante, con actos no interior, marchas e cortes de ruta. Con menor repercusión, en 2007 o CARBAP, illado, convocou unha nova folga.

O descontento acumulado estouparía con toda a súa furia en 2008. O goberno, acurralado entre as contradicións internas dun esquema económico no que o gasto público ascendía vertixinosamente, e unha crise internacional que ameazaba a recuperación local, intentou unha xogada afouta. Coa reforma do esquema de retencións, aspiraba a financiarse aproveitando a forte alza dos prezos internacionais das commodities. Ante isto, a burguesía agropecuaria reaccionou con dureza, convocando unha folga que, pola súa duración, non recoñecía antecedentes na historia arxentina. O grao de mobilización, expresado na cantidade de marchas e cortes de ruta, tamén resultaba inédito. Ao mesmo

11La Nación, 26/ 10/ 1996, 7/ 6/ 1997, 11/ 11/1997, 26/ 1/ 1998, 16/ 5/ 1998, 2/ 8/ 1198, 2/ 1/ 1999, 4/ 6/ 1999 y $20 / 10 / 2000$. 
tempo ocorreu un feito que a moitos resultou novo: a unidade acadada polos representantes corporativos do sector, durante moito tempo enfrontados internamente, que se plasmou na formación da Mesa de Enlace. A pesar de todo, moitos dos elementos que se fixeron presentes, exacerbados, na mobilización de 2008 non eran novos. ${ }^{12} \mathrm{~A}$ historia da protesta agropecuaria en Arxentina, cos seus cambios e continuidades, marca unha senda á que non escapa a conflictividade recente. A continuación, e como peche, intentaremos sistematizar as nosas conclusións sobre este percorrido histórico pola protesta agropecuaria en Arxentina, para ver que ten para dicirnos da estructura económica e as transformacións que sofreu o país nos últimos años.

\section{Transformacións estruturais dun país de base agraria}

A protesta e mobilización da burguesía agropecuaria tivo unha presenza permanente ao longo da historia arxentina. Isto fálanos dun país de base agraria, cuxo desenvolvemento, historicamente, sostívose sobre a base dunha riqueza producida no agro. Unha serie de determinantes naturais (a calidade e situación das terras destinadas á produción agrogandeira) permitiron a xeración desa masa de riquezas, que son materia de disputa. Ao ser unha produción que depende fortemente da terra, un ben monopolizable e non reproducible, os prezos das mercadorías agropecuarias non son determinados, como noutras ramas, polos produtores máis eficientes. Aquí o prezo das mercadorías fíxase en función dos custos das peores leiras, o que dá aos donos das leiras de mellor calidade, que producen con menores custos, unha ganancia extraordinaria denominada renda diferencial. Como en Arxentina sitúanse algunhas das leiras de mellor calidade, afluiu ao país, ao longo da súa historia, unha masa de renda diferencial que serviu para desenvolver forzas produtivas. Como se trata dunha ganancia extraordinaria, que excede o que o burgués individual se apropia como ganancia e necesita para reproducir o capital, esa masa de riqueza pode ser disputada por outros sectores. Daí a presenza do terratenente como suxeito diferenciado do burgués, e tamén a permanente loita entre diferentes sectores que intentan facerse co ingreso. Proba diso é que aínda sofrendo un saqueo permanente desa riqueza (Gráfico 1), a produción agropecuaria non colapsou e a taxa de ganancia agropecuaria mantívose en Arxentina, historicamente, por enriba da industrial (Gráfico 2).

A metodoloxía empregada para o cálculo da renda apropiada polos terratenentes parte das diferenzas entre a taxa de ganancia agraria e a taxa de ganancia industrial en Arxentina. As devanditas taxas calcúlanse ao relacionar as ganancias sobre o capital adiantado tanto fixo como circulante. As ganancias obtéñense de tomar o produto bruto sectorial dun ano e restarlle os salarios e o consumo de capital fixo. Namentres que o capital adiantado corresponde ao stock de capital (que no caso do capital agrario inclúe o stock de gando) e capital circulante (constante e variable) consumido no ano, dividido pola rotación de capital. Ao comparar as taxas de ganancia agraria e industrial, obtense unha diferenza persistente a favor da primeira. Desa diferenza, sábese a porción da plusvalía que flúe ao sector agrario correspondente á ganancia normal en tanto capital industrial aplicado ao agro, e cal en concepto de pago pola propiedade da terra, é dicir, a renda.

Pero como non toda a renda remata cos terratenentes. Existen mediacións no prezo que afectan a ganancia do sector. Por exemplo, os impostos ás exportacións agrarias ou a mediación no comercio exterior pola vía da fixación de prezos. Estes dous mecanismos implican unha redución da ganancia do sector agrario que non afecta ao capital industrial, por tanto é a renda. Estes datos veñen das propias contas fiscais do goberno.

12Reconstrución en base a periódicos de circulación nacional (Clarín, Página/ 12 y La Nación), varias datas. 
Gráfico 1: Cantidade de renda diferencial da terra por destinatario (millóns de \$ de 2004). Arxentina, 1950-2008*

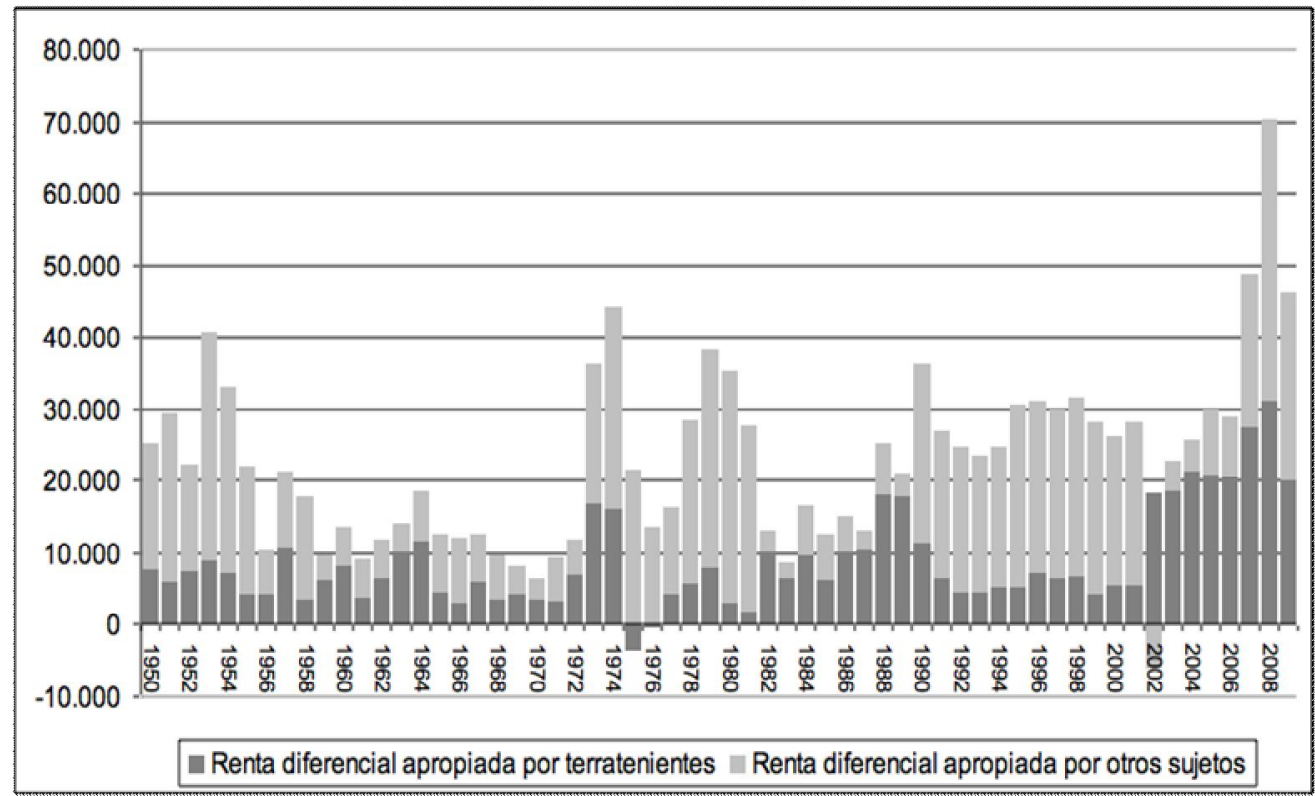

Fonte: elaboración propia en base a datos de Iñigo Carrera (2007).*Os cálculos sobre renda diferencial da terra e os seus cursos de apropiación, por donos da terra e polos que non o son, foron tomados do traballo de Iñigo Carrera.

Gráfico 2: Taxa de ganancia (Tg) do capital agrario, industrial e total do capital social. Arxentina, 1950-1980

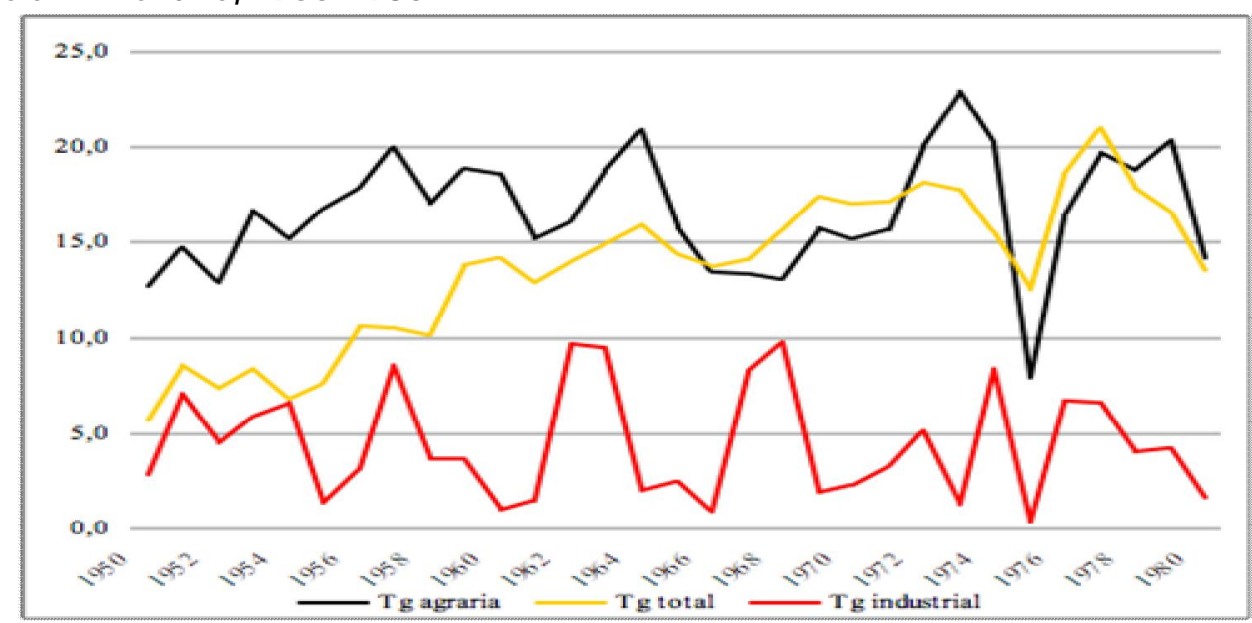

Fonte: elaboración propia en base a datos de Iñigo Carrera (2007).

Máis difícil é o cálculo do efecto da sobrevaloración do tipo de cambio sobre o ingreso do sector agrario. Iñigo Carrera toma como referencia, para ver se o tipo de cambio comercial para as exportacións está por enrima ou por debaixo da valoración, un tipo de cambio de paridade de poder adquisitivo (PPA). Existen moitas metodoloxías e debates sobre como determinar o tipo de cambio de paridade. A adoptada por Iñigo Carrera coñécese como "paridade relativa de poder adquisitivo". O método consiste en determinar un período (1959-1972, para Arxentina) no cal o tipo de cambio exprese unha paridade sen 
distorsións coa moeda estranxeira. Isto débese a que non existe unha tendencia a fortes variacións do tipo de cambio, a que a renda resulta baixa e a que, nos períodos en que a moeda se sobrevalora, despois retoma o nivel de paridade. Unha vez establecida a base, calcúlase a evolución da paridade en función dos cambios nos prezos por efectos monetarios (inflación) e por cambios na produtividade nos EE.UU. e en Arxentina. Conséguese así tipo de cambio de paridade, que despois compara co tipo de cambio comercial para as exportacións agrarias. Da relación defínese se a moeda está sobrevalorada, en paridade, ou subvalorada. Calculado o tipo de cambio, pódese establecer canta capacidad de compra perden os exportadores de mercadorías agrarias e canta gañan os que importan. Como este mecanismo non afecta a ganancia normal do capital industrial agrario, senón a extraordinaria, conclúese que se trata de renda da terra agraria.

Mentres que a renda acadou, para soster o desenvolvemento das forzas produtivas, os conflitos pola apropiación da renda diferencial da terra, non resultaron significativos, e circunscribíronse ás diferentes capas da burguesía que participan na explotación agropecuaria. A iso contribuía unha estrutura na que se diferenciaban claramente distintas capas de produtores, cruzados por contradicións internas. Unha das contradicións máis significativas era a que enfrontaba a burgueses arrendatarios e terratenentes: o enfrontamento entre estas capas da produción foi un dos dinamizadores da conflitividade agropecuaria. Porén, a evolución da actividade determinaría a progresiva desaparición desta contradición, na medida en que os arrendatarios foron accedendo á propiedade da terra. Segundo datos censais, entre 1947 e 1969, na rexión pampeana, os propietarios que explotaban as súas leiras pasaron do 52,1 ao 73,1\%, e os arrendatarios do 37,5 ao $18 \%$. Para 1988, os datos censais indican que eran propietarios das terras que explotaban o 77,9\% dos produtores pampeanos. Á súa vez, boa parte dos arrendamentos na segunda metade do século XX correspondían a propietarios que aumentaban a súa escala produtiva arrendando novas terras. Deste xeito, o arrendo perdeu importancia como forma de acceder á produción (Barsky e Pucciarelli, 1991).

Asemade, un marcado proceso de concentración e centralización da produción ao longo do século tendeu a acortar a fenda entre os produtores de menor tamaño e os máis grandes. Como se observa na Táboa 1, namentres o número total de explotacións presenta unha marcada tendencia descendente, a explotación media aumenta a súa escala. A mecanización das tarefas e a incorporación de innovacións técnicas determinou un permanente aumento da escala óptima, que permite o mellor aproveitamento da maquinaria. Os produtores que non acadaron esta escala foron desprazados da actividade.

\section{Táboa 1: Evolución do número, superficie e media en hectáreas das explotacións agropecuarias da rexión pampeana. Arxentina, 1914-2002}

\begin{tabular}{|l|c|c|c|}
\hline Ano & Explotacións (No) & Superficie (ha.) & Media (ha.) \\
\hline 1914 & 189.271 & 67.242 .813 & 355,3 \\
\hline 1937 & 248.415 & 67.232 .900 & 270,7 \\
\hline 1947 & 282.003 & 71.031 .885 & 251,9 \\
\hline 1960 & 248.220 & 67.710 .787 & 272,8 \\
\hline 1969 & 269.817 & 74.927 .177 & 277,7 \\
\hline 1988 & 188.171 & 70.471 .327 & 374,5 \\
\hline 2002 & 134.759 & 67.223 .891 & 498,8 \\
\hline
\end{tabular}

Fonte: Elaboración propia en base a datos censais, tomados de Barsky e Pucciarelli (1991) e Documento de Traballo № 2 (2005). 
Táboa 2: Distribución da superficie e № de explotacións por estrato na rexión pampeana. Arxentina, 1914-2002

\begin{tabular}{|c|c|c|c|c|c|c|c|c|}
\hline \multirow[t]{3}{*}{ Estratos } & \multicolumn{4}{|c|}{1914} & \multicolumn{4}{|c|}{1969} \\
\hline & \multicolumn{2}{|c|}{$\begin{array}{c}\text { № } \\
\text { de explotacións }\end{array}$} & \multicolumn{2}{|c|}{$\begin{array}{l}\text { Superficie } \\
\text { total en has. }\end{array}$} & \multicolumn{2}{|c|}{$\begin{array}{c}\text { № } \\
\text { de explotacións }\end{array}$} & \multicolumn{2}{|c|}{$\begin{array}{l}\text { Superficie } \\
\text { total en has. }\end{array}$} \\
\hline & № & $\%$ & № & $\%$ & № & $\%$ & № & $\%$ \\
\hline 0 a 25 has & 43.582 & 23,03 & 480.118 & 0,71 & 67.026 & 24,84 & 686.850 & 0,92 \\
\hline 26 a 100 has & 55.940 & 29,56 & 3.428 .251 & 5,10 & 84.935 & 31,48 & 5.134 .366 & 6,85 \\
\hline 101 a 500 has & 70.626 & 37,31 & 15.885 .989 & 23,62 & 82.280 & 30,49 & 16.747 .652 & 22,35 \\
\hline 501 a 1000 has & 9.057 & 4,79 & 6.231 .716 & 9,27 & 22.073 & 8,18 & 13.603 .397 & 18,16 \\
\hline 1001 a 5000 has & 8.139 & 4,30 & 18.463 .952 & 27,46 & 12.049 & 4,47 & 24.823 .276 & 33,13 \\
\hline 5001 e máis has & 1.927 & 1,02 & 22.752 .787 & 33,84 & 1.454 & 0,40 & 13.931 .637 & 18,59 \\
\hline \multirow[t]{3}{*}{ Estratos } & \multicolumn{4}{|c|}{1988} & \multicolumn{4}{|c|}{2002} \\
\hline & \multicolumn{2}{|c|}{$\begin{array}{c}\text { № de } \\
\text { explotacións }\end{array}$} & \multicolumn{2}{|c|}{$\begin{array}{l}\text { Superficie } \\
\text { total en has. }\end{array}$} & \multicolumn{2}{|c|}{$\begin{array}{c}\text { № de } \\
\text { explotacións }\end{array}$} & \multicolumn{2}{|c|}{$\begin{array}{l}\text { Superficie } \\
\text { total en has. }\end{array}$} \\
\hline & № & $\%$ & № & $\%$ & № & $\%$ & № & $\%$ \\
\hline 0 a 25 has & 31.804 & 16,90 & 367.729 & 0,53 & 15.850 & 11,80 & 171.890 & 0,26 \\
\hline 26 a 100 has & 53.268 & 28,30 & 3.237 .359 & 4,60 & 30.367 & 22,50 & 1.710 .099 & 2,54 \\
\hline 101 a 500 has & 73.512 & 39,06 & 17.283.118 & 24,52 & 52.446 & 38,90 & 11.535 .921 & 11,16 \\
\hline 501 a 1000 has & 15.544 & 8,26 & 10.884 .851 & 15,44 & 18.616 & 13,80 & 10.751 .908 & 15,99 \\
\hline 1001 a 5000 has & 12.635 & 6,71 & 25.215 .762 & 35,78 & 15.529 & 11,52 & 27.271 .581 & 40,56 \\
\hline 5001 e máis has & 1.408 & 0,74 & 13.482 .508 & 19,13 & 1.951 & 1,45 & 15.782 .492 & 23,48 \\
\hline
\end{tabular}

Fonte: Documento de Traballo № 2 (2005).

Como se observa na Táboa 2 , a evolución intercensal amosa un proceso permanente de redución das explotacións de menor tamaño. O resultado é unha tendencia á homoxeneización da estrutura agraria, cun acortamento da fenda entre as producións de menor e maior tamaño. O efecto destes fenómenos sobre a protesta agraria é facilmente deducible: a progresiva desaparición da contradicións internas á burguesía agropecuaria, que se manifesta nas tendencias á unidade corporativa en todas as súas capas.

Ao mesmo tempo, estas transformacións da estrutura agropecuaria produciuse en paralelo a unha serie de cambios na estrutura económica do país, que impactan fortemente sobre os determinantes da protesta agraria. Ata a década de 1950 a economía nacional tende a crecer, apoiada sobre un ingreso de renda diferencia que permitiu 0 
aumento da poboación e dunha industria urbana protexida da competencia externa. Porén, a renda vai perdendo, progresivamente, a súa capacidade de impulsar o desenvolvemento económico.

Cara a década de 1950 o proceso revírtese e esta ganancia extraordinaria comeza a amosar os seus límites para seguir sostendo a sectores de escasa competitividade internacional, o que se manifesta na periódica aparición da crise de balanza de pago, no se que denominou o ciclo do stop and go (Iñigo Carrera, 2007; O'Donnell, 2008). É nese momento que as contradicións sociais se agudizan, en particular a que enfronta aos sectores da burguesía industrial urbana, necesitada de transferencias que lle permitan manter a protección do mercado interno e de divisas para a importación de maquinaria e accesorios deste tipo. Neste contexto, como se observa no Gráfico 1, exacérbase a disputa polo excedente agropecuario.

A través da mediación do Estado, que coa institución de políticas impositivas ou de cambio de divisa avanza capturando e redistribuíndo a renda cara aos sectores urbano, a burguesía industrial consegue os recursos necesarios para a súa supervivencia. Cando ese avance sobre a renda diferencial se fai intolerable, é que estoura o conflito coa burguesía agropecuaria, que se mobiliza e se unifica para enfrontarse ao saqueo. Podemos ver no Gráfico 1 que iso é o que ocorre nos momentos críticos que aquí analizamos: 1968-71, 1975, a década de 1990 ou o ano 2008.

\section{Bibliografía}

Barsky, O. y A. Pucciarelli (1991): "Cambios en el tamaño y en el régimen de tenencia de las explotaciones agropecuarias pampeanas", en Barsky (Ed.): El desarrollo agropecuario pampeano. Buenos Aires: GEL.

Barsky, O. y J. Gelman (2009): Historia del agro argentino. Buenos Aires: Sudamericana.

De Olariaga, Nemesio (1994): El ruralismo argentino. Economía ganadera. Buenos Aires, CRA.

Documento de Trabajo № 2 (2005). Rosario: Cátedra de Sociología, Facultad de Ciencias Agrarias-UNR.

Grela, P. (1968): El grito de Alcorta. Historia de la rebelión campesina de 1912. Rosario: Editorial Nuestra Tierra.

Halperin Donghi, T. (1984): "Canción de otoño en primavera: previsiones sobre la crisis de la agricultura cerealera en la Argentina (1894-1930)", Desarrollo Económico 24 (95).

Iñigo Carrera, J. (2007): La formación económica de la sociedad argentina. Buenos Aires: Imago Mundi.

Lázzaro, S. (2005): "El Estado y las políticas agrarias: concepciones y estrategias en el contexto de la crisis hegemónica de la clase dominante (1955-1969)", en Lázzaro, S. y G. Galafassi: Sujetos, política y representaciones del mundo rural. Argentina 1930-1975. Buenos Aires: Siglo XXI.

Míguez, M. (2013): “¿Anticomunistas, antiestatistas, antiperonistas? La 'nacionalización' de la doctrina de seguridad nacional en la Argentina y la legitimación del golpe de Estado de 1966", Revista SAAP 7 (1), pp. 65-95.

O'Donnell, G. (2008): "Estado y alianzas en la Argentina, 1956-1976", en Catacumbas. Buenos Aires: Prometeo.

Sanz Cerbino, G. (2009): "Tiempos violentos. Los paros agrarios de 1975 y la estrategia golpista de la burguesía", Anuario CEICS 3, pp. 33-61. 
Sartelli, E. et al. (2008): Patrones en la ruta. El conflicto agrario y los enfrentamientos en el seno de la burguesía, marzo-julio de 2008. Buenos Aires: Ediciones ryr.

Smith, P. (1986): Carne y política en la Argentina. Buenos Aires: Hyspamérica.

\section{Fontes}

Clarín (periódico de circulación nacional), varios anos.

CRA, SRA, FAA, CONINAGRO y CCEA: El agro y el desarrollo nacional. Conclusiones, Buenos Aires, 17 de novembro de 1970.

Memoria y Balance de la SRA, varios años.

Página/ 12 (periódico de circulación nacional), varios anos.

La Nación (periódico de circulación nacional), varios anos.

La Tierra (semanario oficial de FAA), varios anos.

Revista Galega de Economia at Ideas: http:// https:/ / ideas.repec.org/ s/ sdo/ regaechtml Rules and News of Revista Galega de Economía at: http:// www.usc.es/ econo/ RGE/ benvidag.htm 